\title{
Testing the effectiveness of handwriting interventions: introduction to the special issue
}

\author{
Teresa Limpo $^{1} \cdot$ Rui A. Alves ${ }^{1} \cdot$ Vincent Connelly $^{2}$
}

Published online: 11 May 2018

(c) Springer Science+Business Media B.V., part of Springer Nature 2018

\begin{abstract}
This special issue was born within the COST Action IS1401ELNStrengthening Europeans' Capabilities by Establishing the European Literacy Network, with the major goal of disseminating evidence-based practices to promote handwriting and motivate researchers to move this research field forward. This issue includes five articles testing a different range of interventions to promote handwriting in students with and without disabilities from kindergarten to middle grades, across multiple contexts (viz., United States, Switzerland, Belgium, and Portugal). A final commentary paper closes the special issue with a discussion on the importance of acquiring fluent and legible handwriting along with the contributions and limitations of the investigations presented in the special issue.
\end{abstract}

Keywords Writing · Handwriting · Interventions · Fluency $\cdot$ Legibility

This special issue of Reading \& Writing: An Interdisciplinary Journal was born within the COST Action IS1401ELN-Strengthening Europeans' Capabilities by Establishing the European Literacy Network. ${ }^{1} \mathrm{COST}^{2}$ is a European framework for cooperation in science and technology aimed to close the gap between science, policy makers and society throughout Europe and beyond, by supporting

\footnotetext{
1 http://www.is1401.eln.eu.

2 http://www.cost.eu.

Teresa Limpo

tlimpo@fpce.up.pt

1 Faculty of Psychology and Education Sciences, University of Porto, Rua Alfredo Allen, 4200-135 Porto, Portugal

2 Department of Psychology, Health and Professional Development, Oxford Brookes University, Oxford, UK
} 
transnational cooperation among researchers, engineers and scholars. Within this framework, a group of literacy researchers got together in 2014 and gave rise to the European Literacy Network (ELN), through which reading and writing research communities worldwide have been joining, integrating their findings, and aligning their agendas. Organized into three working groups, this network is aimed at developing an integrated and inclusive approach to foundational literacy across Europe (Working Group 1); devising a comprehensive framework of developmental aspects of literacy and education in a digital world (Working Group 2); and further improving literacy technologies (Working Group 3). Ultimately, ELN intends to bridge the gap between literacy science and education.

The value of reading and writing in contemporary information and technological nations is irrefutable. Nevertheless, for these tools to be effectively used within private and public spheres of economy and society, a certain level of proficiency is required. The problem is that many children simply do not ever master literacy skills at that level. A report by the European Union's High Level Group of Experts on Literacy, adopted by the Council of the European Union in November 2012, noted that: One in five 15 year-olds, as well as nearly 75 million adults, lack basic reading and writing skills, which makes it hard for them to get a job and increases their risk of poverty and social exclusion (European Commission, 2012). Research has been identified as a catalyst for nurturing citizens' literacy capabilities. Still, despite current efforts to develop a common literacy framework, in the last decades, public policy and science have given considerable more attention to reading than to writing.

To master writing, one of the first skills that children need to develop is handwriting (Berninger \& Swanson, 1994). Indeed, even in the current digital era, with technological tools increasingly present in individuals' lives from very early on, in most countries, handwriting is the first taught writing modality and the dominant one throughout education. Across schools worldwide, pens and pencils rather than keyboards are the preferred tool for learning to write and the majority of written texts are produced by hand in most subjects and grade levels (Santangelo \& Graham, 2016). The importance of handwriting in school contexts is reinforced by recent empirical findings. For example, there is evidence showing the advantages of handwriting over typing on either children's early literacy attainments (James \& Engelhardt, 2012) or adults' learning through note taking (Mueller \& Oppenheimer, 2014). Therefore, notwithstanding the heavily-dependent technological societies where today's children grow up, the prevailing pedagogical practices along with scientific evidence on handwriting importance strongly suggest that handwriting should be taught and practiced from very early on.

Writing research has been accumulating evidence about the association between handwriting and composing from primary (Graham, Berninger, Abbott, Abbott, \& Whitaker, 1997) to undergraduate students (Connelly, Dockrell, \& Bernett, 2005). Fortunately, the available body of evidence-based practices to promote handwriting has been increasing in the last years (Alves, Limpo, Salas, \& Joshi, 2018). Recent findings from a meta-analysis suggested that, from kindergarten to ninth grade, students with and without handwriting difficulties benefit from explicit handwriting instruction (Santangelo \& Graham, 2016). An important finding of this meta- 
analysis was that handwriting instruction was associated with impressive improvements not only on students' handwriting skills, but also on the quality, amount, and fluency of their writing. Despite acknowledging the importance of these findings, Santangelo and Graham also highlighted the need for further research testing the impact of handwriting instruction with a wider range of practices and students. This was the main aim of the present special issue, in which we gathered a set of five studies testing the effectiveness of diverse handwriting interventions across different school years and multiple contexts, in students with and without disabilities.

The first article in this special issue by Zemlock, Vinci-Booher and James aimed to examine whether the facilitative effects of handwriting practice on letter knowledge are due to the visually guided production of symbols, involving the finemotor control system, or to a specific effect of writing letters by hand. For that, 79 preschool-aged American children were randomly assigned to one of four groups that underwent 6 weeks of training in writing letters, writing digits, viewing letters, or viewing digits. Results showed that writing either letters or digits, but not viewing, improved letter recognition, which is a component of letter knowledge.

In the second paper, Graham, Harris and Adkins examined the effects of supplemental handwriting and spelling instruction on first graders not acquiring these skills as rapidly as their peers. For that, through the administration of a screening procedure to 336 American children, authors identified 38 children who were randomly assigned by class to treatment (handwriting and spelling instruction) or control (phonological awareness instruction) conditions. Graham et al. found that supplemental handwriting and spelling instruction improved children's handwriting and spelling skills. Moreover, although no effects were found for composition length and quality, the supplemental instruction enhanced students' sentence construction fluency and composition vocabulary.

In the third empirical study included in the special issue, Hurschler Lichtsteiner, Wicki and Falmann examined the added value of combining handwriting and spelling instruction over handwriting-only and spelling-only instruction in Grade 3. For that, 175 typically developing students from the German-speaking part of Switzerland were assigned to one of four conditions: handwriting and spelling training combined, handwriting training only, spelling training only, and control (reading fluency program). Results showed intervention effects neither on writing fluency nor on writing quality. Authors advanced several hypotheses for this lack of effectiveness that might be worthy of testing in future research, such as the examination of moderators of interventions' effects (e.g., duration of the intervention program or degree of handwriting automatization before the intervention).

The fourth paper in the special issue by Van Reybroeck and Michiels explored the benefits of finger writing (i.e., exploration of the shape of the letter with the finger) in French-speaking children with specific language impairment, aged from 7 to 10 years. Authors conducted a pre/posttest multiple single-case intervention study with five children assigned to finger-writing and control conditions. In general, results showed that the three children receiving the finger-writing intervention surpassed their peers in mastering grapheme-phoneme as well as phoneme-grapheme correspondences. Concerning handwriting effects, only two out 
of three treatment children were found to increase their handwriting legibility in response to finger-writing training.

Finally, in the last empirical study included in the special issue, Limpo, Parente and Alves tested the effectiveness of a handwriting intervention in fifth graders displaying less handwriting fluency than their peers. After a screening procedure with 139 children in Grade 5, authors implemented a multiple-probe design across three participants identified to have slow handwriting in the absence of spelling problems. Results showed that the handwriting intervention not only increased students' handwriting fluency, but also improved written composition in terms of clause extension and number of story elements, and strengthened students' selfefficacy beliefs for grammar and usage skills.

The special issue ends with a commentary by Steve Graham, in which he highlights the importance of teaching handwriting and critically reflects on the main contributions provided by each empirical study. After identifying some limitations underlying the studies, Graham additionally suggests new insights and fruitful directions for future research in the field. In particular, echoing the claims of all authors contributing to this special issue, Graham calls for the need of more basic and applied research into handwriting to better understand and facilitate the acquisition and development of such an important writing skill.

Overall, the set of papers gathered in this special issue provides general evidence on the importance of promoting handwriting from kindergarten to middle grades in students with and without disabilities, across different cultural contexts (viz., United States, Switzerland, Belgium, and Portugal). We hope this special issue will motivate further research into the development of evidence-based practices to promote handwriting, including the cross-cultural validation of already validated interventions. In alignment with the ELN goal of promoting interactions between research and practice, it is also our intention that researchers do not confine the dissemination of evidence-based handwriting practices to scientific outlets, but commit themselves to taking them out to school settings.

Acknowledgements This Special Issue benefited from networking at COST Action IS1401 European Literacy Network (www.is1401eln.eu). During its preparation, TL benefited from a grant from the Portuguese Foundation for Science and Technology (Grant Number SFRH/BPD/100494/2014).

\section{References}

Alves, R. A., Limpo, T., Salas, N., \& Joshi, R. M. (2018). Best practices in handwriting and spelling. In S. Graham, C. A. MacArthur, \& M. Hebert (Eds.), Best practices in writing instruction (3rd ed.). New York, NY: The Guilford Press.

Berninger, V. W., \& Swanson, H. L. (1994). Modifying Hayes and Flower's model of skilled writing to explain beginning and developing writing. In E. C. Butterfield (Ed.), Children's writing: Toward a process theory of the development of skilled writing (Vol. 2, pp. 57-81). Greenwich, CT: JAI Press.

Connelly, V., Dockrell, J. E., \& Bernett, J. (2005). The slow handwriting of undergraduate students constrains overall performance in exam essays. Educational Psychology, 25, 99-107. https://doi.org/ 10.1080/0144341042000294912.

European Commission. (2012). EU high level group of experts on literacy: Final report. Luxembourg: Publications Office of the European Union. 
Graham, S., Berninger, V. W., Abbott, R. D., Abbott, S. P., \& Whitaker, D. (1997). Role of mechanics in composing of elementary school students: A new methodological approach. Journal of Educational Psychology, 89, 170-182. https://doi.org/10.1037/0022-0663.89.1.170.

James, K. H., \& Engelhardt, L. (2012). The effects of handwriting experience on functional brain development in pre-literate children. Trends in Neuroscience and Education, 1, 32-42. https://doi. org/10.1016/j.tine.2012.08.001.

Mueller, P. A., \& Oppenheimer, D. M. (2014). The pen is mightier than the keyboard: Advantages of longhand over laptop note taking. Psychological Science, 25(6), 1159-1168. https://doi.org/10.1177/ 0956797614524581.

Santangelo, T., \& Graham, S. (2016). A comprehensive meta-analysis of handwriting instruction. Educational Psychological Review, 28, 225-265. https://doi.org/10.1007/s10648-015-9335-1. 